\title{
Investigation on the Impact of Job Stressors on Nurses in Malaysia
}

\author{
Choi Sang Long ${ }^{1}$, Tan Owee Kowang ${ }^{1}$, Teoh Ai Ping ${ }^{2} \&$ Rajendran Muthuveloo ${ }^{2}$ \\ ${ }^{1}$ Faculty of Management, Universiti Teknologi Malaysia, Johor Bahru, Malaysia \\ ${ }^{2}$ Graduate School of Business, Universiti Sains Malaysia, Penang, Malaysia \\ Correspondence: Choi Sang Long, Faculty of Management, Universiti Teknologi Malaysia, 81310 Johor Bahru, \\ Johor, Malaysia. E-mail: cslong_1@yahoo.com
}

Received: October 21, 2013 Accepted: December 23, 2013 Online Published: January 26, 2014

doi:10.5539/ass.v10n4p67 URL: http://dx.doi.org/10.5539/ass.v10n4p67

\begin{abstract}
Stress can affect individual's performance which in turn can impact an organization's performance. This study was conducted in order to gain a better understanding of what types of situations cause stress in health service providers and how that stress affects job performance especially services that provided to the patients in hospitals. Authors hope to identify the relationship between the job stressors towards job performance of nurses. 300 questionnaires were distributed to qualified nurses in 7 private hospitals across Malaysia. Statistical Package for Social Sciences (SPSS) was used as the software to analyze the data and test the hypotheses. Outcomes from a series of hypothesis tests support the researchers' study that each independent variable has significant relationship to job performance of nurses.
\end{abstract}

Keywords: stress, performance, nurses, role ambiguity, workload

\section{Introduction}

Research has shown that stress is a normal part of human life, even right from birth to death, human being have been found to go through stressful situations (Wong et al., 2002). They further posited that it seems impossible and not beneficial to avoid all stress in life. However, stress is a perceived concept that is caused by anything that unbalances the harmony in one's life (Frassrand, 2005). Several authors have investigated and reported that stressor is any relationship between the person and the environment that is perceived by the person as taxing. The relationship can result in either a beneficial or a harmful outcome (Sonnentag et al., 2010; Schluter et al., 2011; Bakibinga et al., 2012). And have found that different types of stress produce anxiety in individuals, which results in feelings of apprehension that can ultimately lead to negative physical, emotional, cognitive and behavioral symptoms (Boyd \& Nihart, 1998).

Furthermore, hospitals are fast paced health care environments and indicated that newly graduated nurses encounter stressful challenges transitioning from student (graduate) to the professional nurse in the workforce. This issue must be given unabated priority, because loss of the new graduate has financial and patient safety implications (Wu et al., 2012).

Therefore, this study was conducted in order to gain a better understanding of what types of situations cause stress in hospitals how that stress affects job performance. Authors hope to identify the relationship between the job stressors towards job performance of nurses in Malaysia.

\section{Background/Literature}

Daily stressors in life cannot be avoided, nor can major life changes. People respond to stress automatically, mostly out of habit to thousands of events in their lives. Stressful events that change one's life for an extended period can lead to health related problems (Frassrand, 2005). Stress is one of the more commonly documented outcomes of demanding work. Work intensification involves more than longer work hours, highlighting how performance pressures and work effort affect workers. This intensification of work has been linked to rising performance expectations and workloads (Lowe, 2006).

Gorostidi et al. (2007) found that the most significant stressors identified are lack of competence, uncertainty and impotence, being harmed by the relationship with patients, emotional involvement, lack of control in relationships with patients, contact with suffering, and overload.

Conflict arising from the differing demands of home and work is an important source of stress in the nursing 
profession (Hingley et al., 1988). The end result of prolonged exposure to this stress is job burnout. Nowadays, job stress is as much a business issue as it is a health issue. Timothy, Remus and Brent (2006) stated that work-family conflict generate the specific emotional reaction in the form of guilty and hostility at work and at home. Employees in such situation are susceptible to emotional dissonance (Phillips et al., 2007). Such employees are also confronted with emotional exhaustion, which is a form of work related strain and refers to the lack of energy and depletion of emotional resources due to excessive psychological demands (Boles et al., 2000). Emotional dissonance and/or emotional exhaustion may give rise to negative job outcomes such as poor job performance, job dissatisfaction (Abdullah et al., 2012; Long et al., 2012; Solomon et al., 2012; Thwala et al., 2012), reduced organizational commitment, absenteeism, and turnover (Karatepe \& Uludag, 2007; Karatepe \& Aleshinloye, 2009). Besides, there are ample tangible and intangible costs associated with occupational stress and emotional exhaustion/burnout in a world of increasing global competition (Kelloway et al., 2008). There is also a research shown that work-family conflict has been shown to be negatively relate to employees work outcomes such as absenteeism and turnover (Galinsky \& Stein, 1990).

However, stressors, the causes of stress, include any environmental conditions that place a physical or emotional demand on the person. A job stressor has been typically defined as an antecedent condition within ones job or the organization that requires an adaptive response on the part of the employee. The negative reaction to a stressor is called "distress" or "strain" and has been operationalized (Gelsema et al., 2007). Various studies have attempted to find and classify the main stressors that affect nursing staff in general and which could be related to burnout (Garrosa et al., 2006). Garci'a-Izquierdo and Ri'os-Ri'squez (2012) found that one of the fundamental stressor present among nursing staff is excessive workload. This is similar to one of the earlier study by French et al. (2000). Stordeur et al. (2001) in turn, listed stressors in order of severity of their possible effect on workers. At the top of this list was excessive workload, followed by conflicts with doctors, conflicts with colleagues, and lack of clarity in tasks and objectives. As several studies have suggested, nursing staff in general all report similar levels of stress, although there may be a degree of variation depending on the particular unit in which they work (McVicar, 2003). Previous research provides strong evidence that high nursing workloads at the unit level have a negative impact on patient outcomes. Some studies of nurses have shown that higher levels of dissatisfaction and exhaustion are significantly associated with job demands such as high patient to nurse ratios, overtime and increasing patient acuity (Aiken, 2001; O'Brien-Pallas, Thomson, Alksnis, \& Bruce, 2001). As a result, increased workloads and high patient to nurse are resulting in high levels of nurse burnout and dissatisfaction.

Excessive workload may also due to role ambiguity. This refers to unclear role expectations and therefore uncertainty in knowing whether one is meeting role expectations. Role ambiguity contributes to feelings of insecurity and at times confusion. An example of role ambiguity is the expectation that professional nurses be assertive, efficient and independent, and yet acquiesces to the rules and constraints on role performance imposed by hospital bureaucracies (Bellack \& Edlund, 1992). Role ambiguity can be further compounded by role overload, when nurses lack skills in handling role demand, establishing priorities and allocating time wisely. Employees who experience role ambiguity tend to perform at lower levels than employees who have a clear understanding of job requirements and what is expected of them (Bhuian, Menguc, \& Borsboom, 2005). Gorostidi et al. (2007) found that two of the significant stressors identified are role uncertainty and overload. Wu, et al. (2012) further argue that stress among recent nursing graduates are expected to be higher and one of the potential factor of such phenomena is inexperience in prioritizing their workload.

According to Glazer and Gyurak (2008), work-related stressors are defined as markers of the work itself, including aspect of the work physical environment. Physical environment stressors are some stressors that are found in the physical work environment, such as excessive noise, poor lighting and safety hazards (Mcshane \& Von Glinow, 2000). Deming (2000) describes that the physical work environment can cause stress which hinders employees from performing at the desired level. Nurses, physicians and other healthcare employees work under extremely stressful physical conditions. Poor ergonomic design of patient beds and nurses' stations leads to back stress, fatigue and other injuries among nursing staff (Ulrich, Quan, Zimring, Joseph, \& Choudhary, 2004). Many hospital settings have not been rethought as jobs have changed and as a result, the design of hospitals often increases staff stress and reduces their effectiveness in delivering care (Glazer \& Gyurak, 2008).

One other job stressor is procedural injustice. Unfairness, betrayal and procedural injustice are especially pernicious forms of conflict that may undercut organizational commitment and citizenship behaviors (Blader, Steven, \& Tom, 2003; Conway, Neil, \& Rob, 2002). Unfair procedures and unfair treatment lead to stress and burnout. Procedural justice that has implications on persons' sense of self-worth and identity may present another appraisal or belief that moderates the cognitive appraisal process and coping behavior in a stressful 
situation (Lazarus, 1991). Moreover, stress also linked to such negative outcomes as decreased job performance, increased workers' compensation claims and increased sick time (Jex \& Crossley, 2005). For instance, experiencing injustice contributes to such negative outcomes as decreased work performance and increased withdrawal behavior (Blader, Steven, \& Tom, 2003).

\section{Base on the above literature review, following hypotheses are developed:}

$\mathrm{H} 1$ : There is a significant relationship between workload and job performance.

$\mathrm{H1}$ : There is a significant relationship between procedural injustice and job performance.

H3: There is a significant relationship between the role ambiguity and job performance.

$\mathrm{H} 4$ : There is a significant relationship between the work-family conflict and job performance.

H5: There is a significant relationship between physical environment and job performance.

H6: Workload, procedural injustice, role ambiguity, work-family conflict and physical environment do significantly explain job performance.

\section{Methods}

A total of 300 sets of questionnaires were distributed to the nurses in 7 private hospitals in different geographical locations in Malaysia to evaluate the effect of job stressors on job performance by using Statistical Package for Social Sciences (SPSS). The number of useable questionnaires among those retrieved were 261 after those that were not properly completed have been thrown out, thus giving a response rate of $87 \%$. Before starting the data collection, the researchers had run through a Pilot test by using 30 sets of sample.

Job stressors are measured as independent variables and job performance as dependent variable. Job performance is the level of productivity of an individual employee, relative to his or her peers, on several job-related behaviors and outcomes. There are three individual job performance summated to create a measurement of overall job performance in this study which are quality, absenteeism, and new learning.

Pilot test was needed to determine reliability of the sample. It helps researchers to ensure the data collection method was properly designed and the questionnaire was well-organized. In Pilot test, Cronbach's Alpha reliability test was conducted followed by Pearson correlation analysis to test whether the hypotheses of relationship between each independent variable and dependent variable were negatively related. Apart from these, multiple linear regression analysis was conducted to evaluate whether the five independent variables relatively influenced the dependent variable.

Reliability Analyses:

Table 1. Reliability test on independent variables (five job stressors)

\begin{tabular}{ll}
\hline Cronbach's Alpha & N of Items \\
\hline .956 & 23 \\
\hline
\end{tabular}

Table 2. Reliability test on dependent variables (job performance)

\begin{tabular}{ll}
\hline Cronbach's Alpha & N of Items \\
\hline .930 & 15 \\
\hline
\end{tabular}

Table 1 shows the reliability test of independent variables. In the researchers' questionnaire, there are 23 questions that are related to independent variables. The result indicates that the Cronbach's Alpha is 0.956 or 95.60\%. When Cronbach's Alpha is more than 0.9, it shows that there is an excellent reliability in the questionnaires.

Table 2 shows the reliability test of dependent variables. In the questionnaire, there are 15 questions that are related to dependent variables. The result indicates that the Cronbach's Alpha is 0.930 or $93.00 \%$. When Cronbach's Alpha is more than 0.9, it shows that there is an excellent reliability in the researchers' questionnaires. 


\section{Data/Results}

\subsection{Correlation Coefficient Analyses}

According to rules of thumb, correlation coefficients which is between 0.80 to 1.00 are considered very strong relationship, 0.60 to 0.80 are considered strong relationship, 0.40 to 0.60 are considered moderate relationship, 0.20 to 0.40 are considered weak relationship, and 0.00 to 0.20 are considered weak or no relationship.

\subsection{Hypothesis}

From this research, researchers have formulated testable prediction that is also known as hypothesis about the factors that will affect nurses' job performance. As mentioned below are six hypotheses that the researchers have tested:

Table 3. Pearson correlations analysis between job stressor and job performance

\begin{tabular}{ll}
\hline Job Stressor & Job Performance \\
\hline Workload & $-.870^{* *}$ \\
Procedural Injustice & $-.844^{* *}$ \\
Role Ambiguity & $-.684^{* *}$ \\
Work-family Conflict & $-.914^{* *}$ \\
Physical Environment & $-.718^{* *}$ \\
\hline
\end{tabular}

**. Correlation is significant at the 0.01 level (2-tailed).

\section{Hypothesis 1}

H1: There is a significant relationship between workload and job performance.

Table 3 shows the result of correlations coefficient between workload and job performance, which is equal to -0.870 with the P-value 0.000 , lower than 0.05 , indicates that there is a significant relationship between workload and job performance. Therefore, the researchers accept $\mathrm{H} 1$. There is a very strong negative relationship between workload and job performance with correlation coefficient of -0.870 . Every additional unit increase in respondent's stress toward workload will cause 0.870 unit decrease in respondent's job performance.

\section{Hypothesis 2}

$\mathrm{H} 2$ : There is a significant relationship between procedural injustice and job performance.

Table 3 shows the result of correlations coefficient between procedural injustice and job performance, which is equal to -0.844 with the P-value 0.000 , lower than 0.05 , indicates that there is a significant relationship between workload and job performance. Therefore, the researchers accept H2. There is a very strong negative relationship between procedural injustice and job performance with correlation coefficient of -0.844 . Every additional unit increase in respondent's stress toward procedural injustice will cause 0.844 unit decrease in respondent's job performance.

\section{Hypothesis 3}

H3: There is a significant relationship between the role ambiguity and job performance.

Table 3 shows the result of correlations coefficient between role ambiguity and job performance, which is equal to -0.684 with the P-value 0.000 , lower than 0.05 , indicates that there is a significant relationship between workload and job performance. Therefore, the researchers accept H3. There is a strong negative relationship between role ambiguity and job performance with correlation coefficient of -0.684 . Every additional unit increase in respondent's stress toward role ambiguity will cause 0.684 unit decrease in respondent's job performance.

\section{Hypothesis 4}

H4: There is a significant relationship between the work-family conflict and job performance.

Table 3 shows the result of correlations coefficient between work-family conflict and job performance, which is equal to -0.914 with the P-value 0.000 , lower than 0.05 , indicates that there is a significant relationship between workload and job performance. Therefore, the researchers accept H4. There is a very strong negative relationship between work-family conflict and job performance with correlation coefficient of -0.914 . Every additional unit increase in respondent's stress toward work-family conflict will cause 0.914 unit decrease in respondent's job 
performance.

\section{Hypothesis 5}

H5: There is a significant relationship between physical environment and job performance.

Table 3 shows the result of correlations coefficient between physical environment and job performance, which is equal to -0.718 with the P-value 0.000 , lower than 0.05 , indicates that there is a significant relationship between workload and job performance. Therefore, the researchers accept H5. There is a strong negative relationship between physical environment and job performance with correlation coefficient of - 0.718 . Every additional unit increase in respondent's stress toward physical environment will cause 0.718 unit decrease in respondent's job performance.

\subsection{Multiple Linear Regressions}

\section{Hypothesis 6}

H6: Workload, procedural injustice, role ambiguity, work-family conflict and physical environment do significantly explain job performance.

Table 4 shows that $\mathrm{R}$ Square is 0.864 . This explains that $86.40 \%$ of nurses' job performance is affected by workload, procedural injustice, role ambiguity, work-family conflict, and physical environment stressors. However, the remaining $13.60 \%$ are affected by other factors. By referring to Table 5, an ANOVA figures had been computed and shows that $F$ value is 119.791 and $P$ value is 0.000 . Since $P$ value is lower than 0.05 , it shows that there is a significant linear relationship between job stressors and job performance.

From table 6, the researchers can rank independent variables according to how they affect the dependent variable. The negative sign indicates the negative relationship between job stressors and job performance. The Beta under standardized coefficients of five independent variables are -0.141 (workload), -0.119 (procedural injustice), -0.051 (role ambiguity), -0.547 (work-family conflict), and -0.148 (physical environment). Therefore, according Beta, job performance mostly affected by work-family conflict, and then followed by physical environment, workload, procedural injustice and role ambiguity. This indicates that H6 is supported.

Table 4. Model summary

\begin{tabular}{lllll}
\hline Model & $\mathrm{R}$ & $\mathrm{R}$ Square & Adjusted R Square & Std. Error of the Estimate \\
\hline 1 & $.930^{*}$ & .864 & .857 & .33599 \\
\hline
\end{tabular}

*. Predictors: (Constant), Sum of Physical Environment, Sum of Procedural Injustice, Sum of Role Ambiguity, Sum of Workload, Sum of Work-family Conflict

Table 5. Anova

\begin{tabular}{llllll}
\hline Model & Sum of Squares & df & Mean Square & F & Sig. \\
\hline Regression & 67.614 & 5 & 13.523 & 119.791 & $.000^{*}$ \\
Residual & 10.611 & 94 & .113 & & \\
Total & 78.226 & 99 & & & \\
\hline
\end{tabular}

*. Predictors: (Constant), Sum of Physical Environment, Sum of Procedural Injustice, Sum of Role Ambiguity, Sum of Workload, Sum of Work-family Conflict

Table 6. Coefficients

\begin{tabular}{llll}
\hline Model & $\begin{array}{l}\text { Standardized Coefficients } \\
\text { Beta }\end{array}$ & $\mathrm{t}$ & Sig. \\
\hline (Constant) & & 42.317 & .000 \\
Workload & -.141 & -1.420 & .159 \\
Procedural Injustice & -.119 & -1.398 & .165 \\
Role Ambiguity & -.051 & -.905 & .368 \\
Work-family Conflict & -.547 & -5.130 & .000 \\
Physical Environment & -.148 & -2.673 & .009 \\
\hline
\end{tabular}




\section{Discussions}

There are six hypotheses that have been tested in this research. From the result of this study, all the alternate hypotheses are accepted. Summary of the entire hypothesis are shown below:

\subsection{Pearson Correlation}

\section{1) Workload}

$\mathrm{H1}$ : There is a significant relationship between workload and job performance.

In this survey, $\mathrm{H} 1$ is accepted. The result indicates that for workload significant level (P-value) is lower than 0.05 , which means that workload has significant relationship on job performance. Besides, there was a strong negative relationship between workload and job performance. This result is consistent with the finding in literature review (Greenglass \& Burke, 2001; Lowe, 2006). Most of the respondents contribute that they faced mostly insufficient time to perform the tasks, deal with heavy and unsustainable workloads. Usually, workload can be perceived by the pacing of the work, the timing of the work, the variety of the work, the amount of work, and the overwhelming nature of the work. The findings are also connected to that of (Greenglass \& Burke, 2001; Garci'a-Izquierdo et al., 2012) who stated that excessive workload was a most significant predictor of stress with greater workload leading to greater emotional exhaustion and job dissatisfaction. Thus, job dissatisfaction of nurses can lead to absenteeism, poor job performance, and potentially threaten patient care quality. In addition, Lee (2012) support that the factors that causes stress due to heavy workload was significantly related to a poor work motivation which obviously affects the individual performance. Furthermore, pressure pile up for nurses when quality programs which are based on tools, awards criteria, or standards to improve quality of care in the health care industry are implemented (Lee, 2012). In this study, the nurses who deal with greater workload stressors such as insufficient time to complete task, excessive workload and so on, have found to exhibit lower performance. Therefore, the workload stressors in hospital can affect the quality of work and the level of performance among the nurses.

2) Procedural Injustice

$\mathrm{H} 2$ : There is a significant relationship between procedural injustice and job performance.

In this survey, $\mathrm{H} 1$ is accepted. The result shows that for procedural injustice the significant level (P-value) is lower than 0.05 , therefore, the researchers assumed there is a significant relationship between procedural injustice and job performance. Besides, there was a strong negative relationship between procedural injustice and job performance. This result is consistent with the findings of previous authors (Abualrub, 2007). This is due to the fact that most of the midwives had lack of fair treatment (i.e., inadequate recognition, unsatisfactory pay and fringe benefit) thus, leads to deterioration in job performance. Furthermore, (Abualrub, 2007) conclude that inadequate payment of nurses is one of the major reasons for the nurse's dissatisfaction and absenteeism. For instance, the result was further supported by (Pfeffer \& Langton, 1993) who state that experienced injustice would contribute to such negative outcomes as decreased work performance and increased withdrawal behavior. In addition, a similar finding of (Kivimaki et al., 2002) found that procedural injustice was associated with individual's absenteeism in the job performance. From this study finding we assert that nurses experienced a greater procedural injustice in an organization. Thus there is a greater likelihood that they contribute to a decreased rate of job performance.

\section{3) Role Ambiguity}

H3: There is a significant relationship between the role ambiguity and job performance.

In this survey, $\mathrm{H} 1$ is accepted. The result shows for role ambiguity significant level (P-value) is lower than 0.05, which means that role ambiguity has significant relationship on job performance. Besides, there was a strong negative relationship between role ambiguity and job performance. This result is consistent with the finding in literature review, which is supported by (Jackson et al., 1985) that have described role ambiguity has been linked to negative outcomes in occupational settings, such as lower performance. Furthermore, (MacKenzie et al., 1998) also found that role ambiguity is negatively related to motivation and job performance. Other than that, most research suggests that role ambiguity is indeed negatively correlated to job performance. Besides, this result is in line with (Bhuian et al., 2005), employees who experience role ambiguity tend to perform at lower levels than employees who have a clear understanding of job requirements and what is expected of them. Our findings however, reveal that, the nurses with higher levels of role ambiguity were found to exhibit lower performance. Thus, nurses who experience role ambiguity tend to perform at lower levels than those who have a clear understanding of job requirements and what is expected of them. 


\section{4) Work-family Conflict}

H4: There is a significant relationship between the work-family conflict and job performance.

In this survey, $\mathrm{H} 1$ is accepted. The result shows for work-family conflict significant value of -0.914 , is lower than significant level (P-value) 0.05. Therefore, the researchers assumed there is a significant relationship between work-family conflict and job performance. Besides, there was a strong negative relationship between work-family conflict and job performance. This result was consistent with the finding in literature review. Usually, this is due to the stated fact that when the demand of one of these two domains makes it more difficult to meet the demand of others. Nurses experience lack of time and energy to participate in home activities because of the excessive demand of their job. In addition, (Allen et al., 2000) supports that in work-family conflict, it can be expected that this stressor, reflecting incompatible demands at work and home, would be negatively related with performance in family role. On the other hand, (Galinsky \& Stein, 1990) conducted a research and similarly found that work-family conflict seem to be negatively related to employees' performance such as absenteeism and tardiness. However, the studies of (Bacharach, 1991) stated that work family conflict was unrelated to job performance which is inconsistent with our finding.

\section{5) Physical Environment}

H5: There is a significant relationship between physical environment and job performance.

In this survey, $\mathrm{H} 1$ is accepted. The result shows for physical environment significant level (P-value) is lower than 0.05 , which means that physical environment has significant relationship on job performance. Besides, there was a strong negative relationship between physical environment and job performance. This result is consistent with the finding in literature review which is supported by Deming (2000) who describes that the physical work environment can cause stress which hinders employees from performing at the desired level. Thus, physical work environment has a negative effect on nurses not only on the level of stress, but also on the ability to perform. Furthermore, this result is similar with (Newsham et al., 2004), physical environment in which people work affects both job performance and job satisfaction. In this present study, the nurse with greater physical environment stressors such as excessive noise, poor lighting and so on, have lower performance. Therefore, the physical environment stressors in hospital can affect the quality of work and the level of performance among the nurses.

\subsection{Multiple Linear Regressions}

H6: Workload, procedural injustice, role ambiguity, work-family conflict and physical environment do significant explain job performance.

In this survey, $\mathrm{H} 1$ is accepted. The result shows for model summary explains that $86.40 \%$ of nurses' job performance is affected by workload, procedural injustice, role ambiguity, work-family conflict and physical environment (job stressors) which means that these five job stressors do significantly explain the job performance. However, the remaining $13.60 \%$ are affected by other factors. This result is consistent with the finding in literature review (Pekkarinen, 2007; Allen et al., 2000), research on physicians has shown that excessive workload is negatively related to performance on tasks requiring monitoring or constant attention. Pekkarinen (2007), the results sought in the research on the Relationships between Work Stressors and Organizational Performance in Long-Term Care for Elderly Residents provides further evidence for the impact of the procedural injustice on employee performance. More evidence was provided by (Abramis, 1994) on meta-analyses and discovered that relationship between role stressors and subjective indicators of performance has a relationship with job stressors and job performance.

\section{Conclusions}

This research study is important and will bring positive impact to Malaysia's nursing industry and to many parties involved. The research provides a comprehensive examination of the relationship between job stressors and the job performance of nurses. With the result provided, the job stressors were identified in the work environment that has a relationship with job performance of nurses in the survey private hospital. If these job stressors are not managed, it could ultimately affect patient care, employee well-being and organizational performance. This is particularly crucial especially for new nurses who just entered the profession in the health care industry. Managing this stressor can avoid high turnover of nurses in workplaces. Findings from this study will enable organization's top level management to understand the relationship between job stressors and job performance of nurses and therefore evolve preventive strategies to manage these problems. 


\section{Acknowledgement}

Authors wish to acknowledge the Malaysian Ministry of Higher Education and Universiti Teknologi Malaysia under the Research Grant (Vot. 07J89) for supporting and sponsoring this publication.

\section{References}

Abdullah, A., Bilau, A. A., Enegbuma, W. I., Ajagbe, A. M., Ali, K. N., \& Bustani, S. A. (2012). Small and Medium Sized Construction Firms Job Satisfaction and Evaluation in Nigeria. International Journal of Social Science and Humanity, 2(1), 35-40.

Abramis, D. J. (1994). Work role ambiguity, job satisfaction, and job performance: Meta-analysis and review. Psychological Reports, 75, 1411-1433. http://dx.doi.org/10.2466/pr0.1994.75.3f.1411

Abualrub, R. F. (2007). Nursing shortage in Jordan what is the solution? Journal of Professional Nursing, 23(2), 117-120. http://dx.doi.org/10.1016/j.profnurs.2006.07.008

Aiken, L. (2001). Nurses' reports on hospital care in countries. Journal Health Affairs, 20, 43-53. http://dx.doi.org/10.1377/hlthaff.20.3.43

Allen, T. D., Herst, D. E. L., Bruck, C. S., \& Sutton, M. (2000). Consequences associated with work to family conflict: A review and agenda for future research. Journal of Occupational Health Psychology, 5(2), 278-308. http://dx.doi.org/10.1037/1076-8998.5.2.278

Bacharach, S. B. (1991). Work-home conflict among nurses and engineers: Mediating the impact of role stress on burnout and satisfaction at work. Journal of Organization Behavior, 12, 39-53. http://dx.doi.org/10.1002/job.4030120104

Bakibinga, P., Vinje, F. H. F., \& Mittelmark, M. (2012). Factors Contributing to Job Engagement in Ugandan Nurses. International Scholarly Research Network ISRN Public Health, 9. http://dx.doi.org/10.5402/2012/372573

Bauer, J. C. (2002). A longitudinal evaluation of the impact of the organizational structure on role ambiguity and work group performance. Retrieved October 14, 2008, from http://www.clc.uc.edu/ bauerj/JCBauerDissertationFinal.htm

Bellack, J. P., \& Edlund, B. J. (1992). Nursing assessment and diagnosis. Retrieved November 16, 2008, from http://books.google.com.my/book?id=vq7zwOGrcS4C\&pg=PA350\&lpg=PA350\&dq=role+ambiguity+stres sor\&source=web\&ots=bYkEgbnXsG\&sig=RjHsgCgaleCYqBQZK9C4YdfvQ\&hl=en\&sa=X\&oi=book_res ult\&resnum $=8 \& \mathrm{ct}=$ result

Bhuian, S. N., Menguc, B., \& Borsboom, R. (2005). Stressors and job outcomes in sales: A triphasic model versus a linear-quadratic-interactive model. Journal of Business Research, 58, 141-150. http://dx.doi.org/10.1016/S0148-2963(03)00132-2

Boyd, M. A., \& Nihart, M. A. (1998). Psychiatric nursing: Contemporary practice. Philadelphia: Lippincott.

Cropanzano, R., Rupp, D. E., \& Byrne, Z. S. (2003). The relationship of emotional exhaustion to work attitudes, job performance, and organizational citizenship behaviors. Journal of Applied Psychology, 88(1), 160-169. http://dx.doi.org/10.1037/0021-9010.88.1.160

Deming, W. E. (2000). Out of the crisis. Cambridge: MIT Press.

Embriaco, N., Azoulay, E., \& Barrau, K. (2007). High level of burnout in intensivists, prevalence and associated factors. The American Journal of Respiratory and Critical Care Medicine, 175, 686-692. http://dx.doi.org/10.1164/rccm.200608-1184OC

Foxall et al. (1990). A comparison of frequency and sources of nursing job stress perceived by intensive care, hospice and medical-surgical nurses. Journal of Advanced Nursing, 15, 577-584. http://dx.doi.org/10.1111/j.1365-2648.1990.tb01857.x

Frassrand, S. (2005). A comparative analysis of stress levels in undergraduate university students. Retrieved August 3, 2008, from http://www.utc.edu/Administration/DepartmentalHonors/FrassrandS.pdf

French, S. E., Lenton, R., \& Walters, V. (2000). An empirical evaluation of an expanded nursing stress scale. Journal of Nursing Measurement, 8, 161-178.

Galinsky, E., \& Stein, P. J. (1990). The impact of human resource policies on employees: Balancing work/family life. Journal of Family Issues, 11(4), 368-383. http://dx.doi.org/10.1177/019251390011004002 
Garc1'a-Izquierdo, A. L., Moreno, B., \& Garc1'a-Izquierdo, M. (2010). Applying information theory to small group's assessment: Emotions and well-being at work. Spanish Journal of Psychology, 13, 309-328. http://dx.doi.org/10.1017/S1138741600003887

Garci'a-Izquierdo, M., \& Ri'os-Ri'squez, M. I. (2012). The relationship between psychosocial job stress and burnout in emergency department: An exploratory study. Nursing Outlook, 2, 1-8.

Garrosa, E., Moreno, B., \& Liang, Y. (2006). The relationship between socio-demographic variables, job stressors, burnout, and hardly personality in nurses: An exploratory study. International Journal of Nursing Studies, 45, 418-427. http://dx.doi.org/10.1016/j.ijnurstu.2006.09.003

Gelsema, T., Maes, S., \& Akerboom, S. (2007), June 15. Determinants of job stress in the nursing profession: A review. Retrieved November 18, 2008, from https://openaccess.leidenuniv.nl/bitstream/1887/12080/9/02.pdf

Glazer, S., \& Gyurak, A. (2008). Sources of occupational stress among nurses in five countries. Retrieved November 11, 2008, from http://socrates.berkeley.edu/ agyurak/glazer_gyurak_IJIR_08.pdf

Gorostidi, X. Z., Egilegor, X. H., Erice, M. J. A., \& Iturriotz, M. J. U. (2007). Stress sources in nursing practice. Evolution during nursing training. Nurse Education Today, 27(7), 777-787. http://dx.doi.org/10.1016/j.nedt.2006.10.017

Greenglass, E., \& Burke, R. J. (2001). Editorial introduction downsizing and restructuring: Implications for stress and anxiety. Anxiety, stress and coping. An International Journal, 14, 1-13.

Hingley, P., Harris, P., \& Cuoper, C. L. (1988). The nurse stress index. Yorkshire, England: Resource Assessment and Development Station.

Jackson, S. E., \& Schuler, R. S. (1985). A meta-analysis and conceptual critique of research on role ambiguity and role conflict in work settings. Organizational Behavior and Human Decision Processes, 36, 16-78. http://dx.doi.org/10.1016/0749-5978(85)90020-2

Jenkins, M. (2007). Vault career guide to nursing. Retrieved August 14, 2008, from http://books.google.com.my/books?id=Rasm7VpipIIC\&dq=history+of+nursing+industry\&source=gbs_sum mary_s\&cad $=0$

Jex, S. M., \& Crossley, C. D. (2005). Organizational consequences. In J. Baring, E. K. Kelloway, \& M. Frone (Eds.), Handbook of work stress (pp. 575-599). Thousand Oaks, CA: Sage Publications. http://dx.doi.org/10.4135/9781412975995.n24

Karatepe, M. O., \& Aleshinloye, D. K. (2009). Emotional dissonance and emotional exhaustion among hotel employees in Nigeria. International Journal of Hospitality Management, 28, 349-358. http://dx.doi.org/10.1016/j.ijhm.2008.12.002

Karatepe, M. O., \& Uludag, O. (2007). Conflict, exhaustion, and motivation: A study of frontline employees in Northern Cyprus hotels. International Journal of Hospitality Management, 26(3), 645-665. http://dx.doi.org/10.1016/j.ijhm.2006.05.006

Kivimaki, M., Elovanio, M., Vahtera, J., \& Ferrie, J. E. (2002). Organizational justice and health of employee: Prospective cohort study. Occupational and Environmental Medicine, 60, 27-34. http://dx.doi.org/10.1136/oem.60.1.27

Lazarus, R. S. (1993). From psychological stress to the emotions: A history of changing outlooks. Annual Review of Psychology, 44, 1-21. http://dx.doi.org/10.1146/annurev.ps.44.020193.000245

Lee, D. H. (2012). Implementation of quality programs in health care organizations. Service Business, 6, 1-18. http://dx.doi.org/10.1007/s11628-012-0141-2

Long, C. S., Perumal, P., \& Ajagbe, A. M. (2012). The Impact of Human Resource Management Practices on Employees' Turnover Intention: A Conceptual Model. Interdisciplinary Journal of Contemporary Research in Business, 4(2), 223-230.

Lowe, G. (2006). Under pressure: Implications of work-life balance and job stress. Retrieved August 6, 2008, from http://www.grahamlowe.ca/documents/182/Under\%20Pressure\%2010-06.pdf

Loyd, K. (2006). A study of the relation between work experience and occupational work ethic characteristic of Baccalaureate nursing students. Retrieved December 14, 2008, from http://digital.library.unt.edu/permalink/meta-dc-52656688674.pdf

MacKenzie, S. B. (2008). Managing job stress. Retrieved November 11, 2008, from 
http://spot.pcc.edu/ rjacobs/career/managing_job_stress.htm\#Job\%20Stress\%20Research\%20Surveys

MacKenzie, S. B., Podsakoff, P. M., \& Ahearne, M. (1998). Some possible antecedents and consequences of in-role and extra-role sales person performance. Journal of Marketing, 62, 87-98. http://dx.doi.org/10.2307/1251745

Mcshane, S. L., \& Von Glinow, M. A. (2000). Organizational behavior. New York: McGraw-Hill.

McVicar, A. (2003). Workplace stress in nursing: A literature review. Journal of Advance Nursing, 44, 633-642. http://dx.doi.org/10.1046/j.0309-2402.2003.02853.x

Ministry of Health Malaysia. (2007). Health Facts 2006. Retrieved August 14, 2008, from http://www.moh.gov.my/static/health_facts_2006.pdf

Neil, C., \& Rob, B. B. (2002). Full-time versus part-time employees: Understanding the links between work status, the psychological contract, and attitudes. Journal of Vocational, 47, 213-227.

Newsham, G. R., Veitch, J., Charles, K. E., Clinton, J. G., Marquardt, J. G., Bradley, J. S., ... Rea don, J. (2004). Environmental satisfaction in open plan environments: Relationships between physical variables. Canada: Research in Construction. Technical Report RR-153, Ottawa, Institute for Research in Construction, National Research Council Canada.

O'Brien-Pallas, L., Thomson, D., Alksnis, C., \& Bruce, S. (2001). The economic impact of nurse staffing decisions: Time to turn down another road. Hospital Quarterly, 4(3), 42-50.

Pekkarinen, L. (2007). The relationships between work stressors and organizational performance in long-term care for elderly residents. Retrieved January 16, 2009, from https://oa.doria.fi/bitstream/handle/10024/32995/therelat.pdf?sequence=1

Pfeffer, J., \& Langton, N. (1993). The effects of wage dispersion on satisfaction, productivity, and working collaboratively: Evidence from college and university faculty. Administrative Science Quarterly, 38, 382-407. http://dx.doi.org/10.2307/2393373

Phillips, B., Tan, T. T. W., \& Julian, C. (2007). The theoretical underpinnings of emotional dissonance: A framework and analysis of propositions. Journal of Services Marketing, 20(7), 471-478. http://dx.doi.org/10.1108/08876040610704900

Richard, E. B. (1982). The competent manager: A model for effective performance. Retrieved August 6, 2008, from

http://books.google.com/books?hl+en\&lr+id=KmFR7BnLdCoC\&oi=fnd\&pg=PP19\&dq=Definition + of + job +performance\& ots=wrbNTpPpXG\&sig=VAWzH719NtW-19HqOMkuLuWr8\#PPA,M1

Schluter, P. J., Turner, C., Huntington, A. D., Bain, C. J., \& Mcclure, R. J. (2011). Work/Life Balance and Health: The NursesE-Cohort Study. International Nursing Review, 58, 28-36. http://dx.doi.org/10.1111/j.1466-7657.2010.00849.x

Slaughter, A. (2007). Stress and performance. Retrieved August 25, 2008, from http://www.tamu.edu/classes/slaughter/performance.pdf

Solomon, O., Mehdi, B. T. Z., \& Ajagbe, A. M. (2012). Employee Motivation and Organizational Performance in Multinational Companies: A Study of Cadbury Nigeria Plc. International Journal of Research in Management and Technology (IJRMT), 2(3), 303-312.

Sonnentag, S., Iris, K., \& Charlotte, F. (2010). Job stressors, emotional exhaustion, and need for recovery: A multi-source study on the benefits of psychological detachment. Journal of Vocational Behavior, 76, 355-365. http://dx.doi.org/10.1016/j.jvb.2009.06.005

Steven, L. B., \& Tom, R. T. (2003). What constitutes fairness in work settings: A four-component model of procedural justice. Human Resource Management Review, 13, 107-126. http://dx.doi.org/10.1016/S1053-4822(02)00101-8

Stordeur, S., D'Hoore, W., \& Vandenberghe, C. (2001). Leadership, organizational stress and emotional exhaustion among hospital nursing staff. Journal of Advanced Nursing, 35, 533-542. http://dx.doi.org/10.1046/j.1365-2648.2001.01885.x

Tesluk, P. E., \& Jacobs, R. R. (1998). Toward an integrated model of work experience. Personnel Psychology, 51, 321-355. http://dx.doi.org/10.1111/j.1744-6570.1998.tb00728.x

Thwala, D. W., Ajagbe, A. M., Long, C. S., Bilau, A. A., \& Enegbuma, W. I. (2012). Sudanese Small and 
Medium Sized Construction Firms: An Empirical Survey of Employee Satisfaction and Performance. Journal of Basic, Applied Social Research, 2(8), 7414-7420.

Ulrich, R., Quan, X., Zimring, C., Joseph, A., \& Choudhary, R. (2004). The role of the physical environment in the hospital of the 21st century: A once-in-a-lifetime opportunity. Retrieved August 16, 2008, from http://www.rwjf.org/files/publications/other/RoleofthePhysicalEnvironment.pdf

Wong, D., Perry, S., \& Hockenberry, M. (2002). Maternal Child Nursing Care (2nd ed.). St. Louis: Mosby.

$\mathrm{Wu}$ et al. (2010). Occupational stress among hospital nurses: Cross-sectional survey. Journal of Advanced Nursing, 66, 627-634. http://dx.doi.org/10.1111/j.1365-2648.2009.05203.x

Wu, T. Y., Fox, D. P., Stokes, C., \& Adam, C. (2012). Work-related stress and intention to quit in newly graduated nurses. Nurse Education Today, 32(6), 669-674. http://dx.doi.org/10.1016/j.nedt.2011.09.002

Yavas, U., Babakus, E., \& Karatepe, O. M. (2008). Attitudinal and behavioral consequences of work-family conflict and family-work conflict: does gender matter? International Journal of Service Industry Management, 19(1), 7-31. http://dx.doi.org/10.1108/09564230810855699

\section{Copyrights}

Copyright for this article is retained by the author(s), with first publication rights granted to the journal.

This is an open-access article distributed under the terms and conditions of the Creative Commons Attribution license (http://creativecommons.org/licenses/by/3.0/). 